This item was submitted to Loughborough's Research Repository by the author.

Items in Figshare are protected by copyright, with all rights reserved, unless otherwise indicated.

\title{
Deconstructing the relationship between entrepreneurial orientation and business performance at the embryonic stage of firm growth
}

PLEASE CITE THE PUBLISHED VERSION

https://doi.org/10.1016/j.indmarman.2006.04.003

\section{PUBLISHER}

(C) Elsevier

VERSION

AM (Accepted Manuscript)

\section{PUBLISHER STATEMENT}

This work is made available according to the conditions of the Creative Commons Attribution-NonCommercialNoDerivatives 4.0 International (CC BY-NC-ND 4.0) licence. Full details of this licence are available at: https://creativecommons.org/licenses/by-nc-nd/4.0/

\section{LICENCE}

CC BY-NC-ND 4.0

\section{REPOSITORY RECORD}

Hughes, Mathew, and Robert E. Morgan. 2019. "Deconstructing the Relationship Between Entrepreneurial Orientation and Business Performance at the Embryonic Stage of Firm Growth". figshare. https://hdl.handle.net/2134/26377. 


\title{
Deconstructing the Relationship between Entrepreneurial Orientation and Business Performance at the Embryonic Stage of Firm Growth ${ }^{1}$
}

IMM ref \# 04-253RR

First submitted: December 2004

Resubmitted (1): June 2005

Resubmitted (2): $6^{\text {th }}$ December 2005

\author{
Mathew Hughes ${ }^{2}$ \\ Institute for Enterprise \& Innovation \\ Nottingham University Business School \\ Jubilee Campus, Wollaton Road \\ Nottingham NG8 1BB \\ United Kingdom \\ Tel: +44 (0)115 8467747 \\ Fax: +44 (0)115 8466650 \\ E-mail: mat.hughes@nottingham.ac.uk
}

\author{
Robert E. Morgan \\ Cardiff Business School \\ Cardiff University \\ Colum Drive, Cardiff CF10 3EU \\ United Kingdom \\ Tel: +44 (0)29 20870001 \\ Fax: +44 (0)292087 4419 \\ E-mail: morganre@cardiff.ac.uk
}

Acknowledgement:

The authors would like to express their thanks to Peter LaPlaca and the anonymous IMM

Reviewers that commented on previous versions of this manuscript. We are grateful to them for their insightful comments.

\footnotetext{
${ }^{1}$ Previously submitted under the title: 'The Growth of High-Technology Incubating Firms: Entrepreneurial Orientation and Business Development in New Firms'

${ }^{2}$ Corresponding author.
} 


\section{AUTHOR BIOS}

Mathew Hughes is a Lecturer in Entrepreneurship at the University of Nottingham Institute for Enterprise and Innovation (UNIEI) at Nottingham University Business School. Prior to this, he completed his doctorate in strategic management and entrepreneurship at University of Wales, Aberystwyth, U.K., where he also gained a first Degree (with first class honors) and Masters Degree (distinction) in Business and Management. His dissertation focused on the strategic and entrepreneurial management of business incubation to drive strategic growth in incubating firms in a U.K. context. The United Kingdom Business Incubation (UKBI) supported this research.

Robert E. Morgan is Associate Dean and is the Sir Julian Hodge Professor of Marketing and Strategy at Cardiff Business School, Cardiff University. His main research interests include market-based organizational learning, international marketing, strategic alliance management, and strategic entrepreneurship. He has published widely on these topics and consulted with many global firms and government departments on managing these issues. 


\title{
Deconstructing the Relationship between Entrepreneurial Orientation and Business Performance at the Embryonic Stage of Firm Growth
}

\author{
ABSTRACT \\ Studies of entrepreneurial orientation tend to examine its three most common features only (risk- \\ taking, innovativeness, and proactiveness), merging these into a gestalt construct of \\ entrepreneurial orientation and then analyzing its effect on business performance. This is in \\ contrast to Lumpkin and Dess who stressed an entrepreneurial orientation is best characterized \\ by five dimensions which can vary independently and may not be equally valuable across \\ performance metrics or at different stages of development. We rectify these problems by \\ examining the independent impact of risk-taking, innovativeness, proactiveness, competitive \\ aggressiveness, and autonomy on performance of young high-technology firms at an embryonic \\ stage of development. Our results support those Lumpkin and Dess. Only proactiveness and \\ innovativeness have a positive influence on business performance while risk-taking has a \\ negative relationship. Competitive aggressiveness and autonomy appear to hold no business \\ performance value at this stage of firm growth. From these results, we offer implications for \\ managers in addition to guidance for future research.
}

Keywords: Entrepreneurial orientation; risk-taking, innovativeness, proactiveness, competitive aggressiveness, autonomy, young firms; business performance. 


\section{INTRODUCTION}

Today’s business environment is repeatedly described as complex and uncertain (Dreyer and Grønhaug, 2004; Slater and Olson, 2002). This can place emerging young firms in vulnerable positions by compromising their ability to compete against established competitors. To compete under such conditions, normative theory encourages young firms to hone their entrepreneurial capabilities (Lee, Lee, and Pennings, 2001; Wiklund and Shepherd, 2005) so as to launch speedy and stealthy attacks on rivals (Chen and Hambrick, 1995).

Seminal work by Lumpkin and Dess (1996) defined an entrepreneurial orientation (EO) as the decision-making styles, processes, and methods that inform a firm’s entrepreneurial activities. It has also been described as a form of strategic orientation (Wiklund and Shepherd, 2003, 2005). Lumpkin and Dess (1996) drew on extensive research to characterize an EO as being the product of five dimensions_risk-taking, innovativeness, proactiveness, competitive aggressiveness, and autonomy. Research efforts since then have repeatedly sought to prove that EO carries valuable rewards in terms of business performance. Several studies have reported positive associations (e.g., Wiklund, 1999; Wiklund and Shepherd, 2003, 2005; Zahra, 1991; Zahra and Covin, 1995) but there are exceptions to this (e.g., Hart, 1992; Matsuno, Mentzer, and Özsomer, 2002; Morgan and Strong, 2003; Smart and Conant, 1994; Slevin and Covin, 1990). It would appear that EO sometimes, but not always, contributes to improved business performance.

The important question, therefore, is why the influence of EO on performance might be so inconsistent. Despite the wide-ranging attention devoted to EO, few studies have expressly examined Lumpkin and Dess’ (1996) five-dimension framework of EO. The tendency has been instead to study only three of the five dimensions, commonly risk-taking, innovativeness, and proactiveness as characterized by Miller (1983). Moreover, researchers have almost exclusively 
adopted an aggregate (or higher-order) approach to the assessment of EO. That is, risk-taking, innovativeness, and proactiveness are measured as independent dimensions and then a composite EO scale is created into a combined gestalt construct for further analysis. The problem with this approach is that it neglects the individual influence of each dimension and assumes a universal and uniform influence by each dimension. In contrast, Lumpkin and Dess (1996) state that each dimension can vary independently and might not necessarily be beneficial or even desirable at different points in time. As a result, the coarse-grained conclusions from much of the extant EO empirical research require that this fundamental caveat be explored further.

For emerging young firms with limited resource endowments, understanding which of the five EO dimensions are most valuable to securing improved performance at their potentially vulnerable stage of development is an important priority. It is conceivable that all five dimensions may be beneficial but it is equally plausible that only a sub-set of dimensions may be valuable. At present, research into EO has ignored these issues and instead has consistently only made only a partial analysis of the Lumpkin and Dess (1996) framework and have adopted a summative approach to their examination of EO, which renders individual uniqueness obsolete. We seek to contribute to our understanding of the EO construct by rectifying these omissions and responding to the following research question: Are all five dimensions of the Lumpkin and Dess (1996) EO framework equally valuable to firms at an embryonic stage of development?

\section{THEORETICAL FRAMEWORK}

This study differs from the majority of existing studies in that it examines the relationship between EO and performance at the uni-dimensional level in emerging young firms in order to assess specifically which dimensions of EO are most valuable to securing performance at that embryonic stage of development. To further differentiate from extant studies, we examine the 
EO construct as specified by the conceptualization of Lumpkin and Dess (1996), rather than merely adopt a selective approach to the analysis of EO.

The majority of studies into EO tend to adopt the Miller (1983) definition of an entrepreneurial firm and extrapolate it to EO. Miller (1983) defined an entrepreneurial firm as one that "engages in product market innovation, undertakes somewhat risky ventures, and is first to come up with 'proactive' innovations, beating competitors to the punch" (p. 771). From this definition, scholars have repeatedly pinpointed and studied three core dimensions said to classify an EO these being risk-taking, innovativeness and proactiveness (e.g., Barringer and Bluedorn, 1999; Covin and Slevin, 1989; Naman and Slevin, 1993; Wiklund, 1999; Wiklund and Shepherd, 2003, 2005; Zahra and Covin, 1995). Lumpkin and Dess (1996) on the other hand argue that a coherent classification of an EO consists of five dimensions not three. In addition to those identified by Miller (1983), Lumpkin and Dess (1996) conceptualize competitive aggressiveness and autonomy as two additional dimensions of a coherent EO.

Lumpkin and Dess (1996) define EO as the methods, practices, and decision-making styles managers use to act entrepreneurially and can be thought of as a type of strategic orientation insofar as it captures how a firm intends to compete. An EO is operationalized through risk-taking, innovativeness, proactiveness, competitive aggressiveness, and autonomy each of which can vary independently (Lumpkin and Dess, 1996). Risk-taking reflects an acceptance of uncertainty and risk inherent in original activity and is typically characterized by resource commitment to uncertain outcomes and activities. Innovativeness captures a bias toward embracing and supporting creativity and experimentation, technological leadership, novelty and R\&D in the development of products, services and processes. Proactiveness relates to a forward-looking perspective where companies actively seek to anticipate opportunities to 
develop and introduce new products to obtain first-mover advantages and shape the direction of the environment. Competitive aggressiveness conveys the intensity with which a firm chooses to compete and attempts to surpass competitors reflecting a bias toward out-maneuvering and outdoing rivals. Autonomy describes giving an individual or team within the firm the necessary authority and independence to develop business concepts and visions and carry them through to completion.

As yet, it is largely unclear how these five dimensions individually map onto business performance. It is evident that all or at least a combination of dimensions exhibit some relationship with business performance since there have been widespread reports of a positive relationship between EO and performance (e.g., Wiklund, 1999; Wiklund and Shepherd, 2003, 2005; Zahra, 1991; Zahra and Covin, 1995). Yet some dimensions might 'carry' others that may have no separate influence on performance. This appears a likely possibility because the EOperformance relationship has been called into question in several studies with a number finding little or no association and others reporting even a negative relationship (e.g., Hart, 1992; Matsuno et al., 2002; Morgan and Strong, 2003; Smart and Conant, 1994).

Studies have ignored an analysis of the EO dimensions and as such we have little knowledge of whether each is equally important or even necessary to secure improved performance in emerging young firms. Lumpkin and Dess (1996) reasoned that EO dimensions might lead to favorable outcomes on one performance dimension but unfavorable outcomes on another and this may also depend on different firm conditions. These authors further suggested that as firms change, the nature of their EO might change with it. Age and size determine much of firms' needs and Lumpkin and Dess (1996) highlighted that very young firms might exhibit dependency on innovativeness and risk-taking, for example, more than older and larger firms 
which may require greater autonomy to achieve improved performance. They further raise the question of when a firm might cease to be entrepreneurial but go on to suggest that rather than appearing to cease, the case may be that the firm's EO changes to better suit its strategic and market needs. They conclude that not all EO dimensions may be present or valuable as it depends on firm context. From these issues, to advance the Lumpkin and Dess (1996) framework, it is clear that research is needed to examine how each individual dimension of an EO might influence business performance, and, it is necessary to take into account the stage of development of firms to be examined. Accordingly, in the context of this study, emerging young firms may implement each dimension of EO simultaneously without any degree of certainty as to a possible business performance effect. The next section will explore each dimension in turn and hypothesize why a specific dimension might have a positive influence on business performance in emerging young firms.

\section{HYPOTHESES}

Risk-taking represents a willingness to commit resources to implement projects, activities, and solutions that contain inherently a high level of uncertainty regarding the likely outcomes (Lumpkin and Dess, 1996). When deciding to take risks, firms must tolerate one of two possible scenarios - the first being the risk of failing and second the risk of missing out on an opportunity (Dickson and Giglierano, 1986). The former is caused by fear whereas the latter is caused by inaction. A tolerance of risk-taking orients the firm toward action and induces it to embrace uncertainty. Timely risk-taking has been associated with strategic decision speed and both have subsequently been linked to improved business performance (Eisenhardt, 1989). Without a degree of risk-taking, firms delay or refrain from introducing innovations, from undertaking exploitative activities and react conservatively to changing market conditions. The 
result would be weaker performance as the firm would do little to seize customer and market opportunities.

Risk-oriented firms combine opportunity-seeking behavior with constructive risk-taking to generate a bias for exploration and exploitation (Baird and Thomas, 1996; Lumpkin and Dess, 1996). This prevents the firm from being lulled into inertia, inaction, and adherence to traditions (Busenitz and Barney, 1997; Miller and Friesen, 1982). Risk-taking managements usually seize opportunities and make commitments of resources before fully understanding what action needs to betaken (Covin and Slevin, 1991). Such an approach seeks to take advantage of evolving situations by capitalizing on the fact that markets rarely stabilize for any length of time. Risk aversion renders firms passive to developing new market opportunities which is likely to deteriorate performance in age of rapid change (Miller and Friesen, 1982).

Risk-taking can carry costs but where customer demands change incessantly, the thrust of research opinion suggests that firms need to demonstrate a willingness to take risks and challenge the existing order of business to secure performance. Accordingly, we hypothesize the following:

Hypothesis 1: Risk-taking is positively related to business performance.

Innovativeness represents a bias toward embracing and supporting creativity, experimentation, technological leadership, and R\&D in the development of products, services, and processes to generate novel solutions to customer needs and problems. It is said to be present when firms pursue active implementation of new ideas, products or processes not merely their generation (e.g., Hurley and Hult, 1998). A strong emphasis on innovativeness mobilizes entry into new arenas, renews the firm's presence in existing ones and embodies a capability to explore new possibilities (Cho and Pucik, 2005; Garud and Nayyar, 1994; Hult and Ketchen, 
2001). As such, innovativeness is a chief means to create differentiation and develop solutions that undermine those of competitors.

Brüdel and Preisendörfer (2000) identified innovation to be the single most important firm predictor of firm growth. Calantone, Çavuşgil, and Zhao (2002) found that firm innovativeness has a positive impact on performance and contributes to competitive advantage by facilitating creative thinking within a firm's learning activities. Innovativeness also improves the application of market intelligence acquired through market orientation activities, which can benefit performance (Han, Kim, and Srivastava, 1998; Hurley and Hult, 1998). Also, Hult, Hurley, and Knight (2004) uncovered in their study that innovativeness benefits business performance regardless of market turbulence. Innovativeness changes how a firm applies market information (e.g., Slater and Narver, 1995) and together informs the generation of intelligent solutions.

Innovativeness in activities can potentially carry costs however and depends largely on commercialization for the success of its outcomes but given that it changes how firms apply many of their learning and market mechanisms by establishing new insight and perspective, it is likely to contribute to business performance. Accordingly, the following hypothesis is formed:

Hypothesis 2: Innovativeness is positively related to business performance.

Proactiveness represents a forward-looking perspective where firms actively seek to anticipate opportunities to develop and introduce new or improved products, instigate changes to current strategies and tactics, and detect future trends in the market (Lumpkin and Dess, 1996; Slater and Narver, 1995). Its goal is to secure first-mover advantage in the short term and shape the direction of the market environment in the long term. 
Increasing the firm's receptiveness to market signals and awareness of customers' needs (expressed or latent) are two of the main advantages offered by proactiveness. Studies have reported high performance returns to proactive firms because of their responsiveness to market signals (e.g., Day and Wensley, 1988; Wright, Kroll, Pray, and Lado, 1995). Proactive firms, through proprietary learning and experience effects gained over time, tend to be more attuned to changes and trends in the marketplace, which yields opportunities to the firm to meet expressed and latent needs ahead of competitors (Hamel and Prahalad, 1991). By actively anticipating and preparing for change, proactive firms are in a better position to seize market share and customers quickly when change occurs by mobilizing resources far in advance of rivals. In doing so, the proactive firm remains a step ahead of less responsive competitors.

Proactiveness in firms is characterized by intentional change. That is, forcibly acting on information to make change not merely anticipating it (Bateman and Crant, 1999). This alleviates the risk of complacency by ensuring firms are better placed to serve markets in the short term and shape them in the longer term. The emphasis on anticipating and acting on future needs orients the firm to seize initiative and act opportunistically in the marketplace thereby shaping demand (Miller and Friesen, 1978; Venkatraman, 1989). Proactiveness is likely to be valuable in securing superior performance returns because it implies customer-centrality given the need to understand customers, ascertain and exploit their needs, and actively deconstruct the value package of competitors to generate superior offerings.

By being 'inert to inertia', proactive firms can potentially secure valuable performance rewards. The proactive firm adopts continuous environmental scanning and acts in advance of change to better serve customers and markets rather than allow its destiny to be guided by 
external forces. Proactiveness leverages the firm's responsiveness capability and propensity to act to meet new circumstances. Accordingly, it is hypothesized that:

Hypothesis 3: Proactiveness is positively related to business performance.

Competitive aggressiveness encapsulates the intensity of a firm's efforts to outperform and undermine its industry rivals (Lumpkin and Dess, 2001). It can take the form of deliberate action as well as reactive action. Firms that are highly aggressive see competitors as enemies that must be conquered. Aggressiveness can be implemented through the mobilization of resources to launch direct attacks on competitors with the aim of overwhelming their market efforts, steadily erode their competitive strengths, or establish advantage through continuous offensive tactics (Davidson, 1987). In contrast to proactiveness, competitive aggressiveness mobilizes continuous competitor assessment above environmental assessment so that opportunities to exploit the firm’s strengths and competitors’ weaknesses are sought and taken advantage of. The aggressive firm sees value as accruing from leveraging adaptive capabilities to consistently undermine competitors' efforts in the market as opposed to adopting a passive stance to competition.

The aggressive firm relies on offense as opposed to defense in its approach to competition. Aggressiveness can improve performance because the emphasis on out-doing and out-maneuvering competitors strengthens the firm's competitiveness at the expense of rivals (Lumpkin and Dess, 1996). Examples of the manifestation of such an aggressive competitive strategy include aggressive price competition, market entry with a new or superior offering, fastfollowing a rival into a market, continuously exploiting information, and using unconventional surprise tactics. Such an emphasis on acquiring market share and customers by aggressively targeting rivals’ weaknesses should improve performance because it undermines competitors’ 
ability to compete and restricts the ability of competitors to anticipate and respond to what the aggressive firm will do next. Since the aggressive firm does not sit still and constantly implements incremental and adaptive change to undermine competitors, it is hypothesized that:

Hypothesis 4: Competitive aggressiveness is positively related to business performance.

Autonomy conveys the freedom to employees to encourage them to be self-directed, to exercise creativity, pursue opportunities, and champion new ideas which are essential for effective entrepreneurial activity to occur (Lumpkin and Dess, 1996). This requires policies of empowerment, open communication, unrestricted access to information, and authority to think and act without interference (Engel, 1970; Spreitzer, 1995).

By establishing autonomy, managers demonstrate to employees their faith in their ability to perform effectively outside the rubric of firm constraints. Such autonomy then encourages employees to participate in change and become actively involved in entrepreneurial activity. This is likely to be a critical success factor because all entrepreneurial activity must be undertaken by employees. If employees are constrained in the actions and activities they can undertake without managerial consent, entrepreneurial activity is likely to fail and the performance of the firm is likely to suffer as employees fail to deviate when necessary from established practices or implement change quickly.

Autonomy is, therefore, an important driver of flexibility, which is an essential attribute if a firm is to be able to respond promptly to environmental change and market signals by quickly reconfiguring its actions and activities (e.g., Grewal and Tansuhaj, 2001). Flexibility is created when people within the firm are given freedom to apply their human capital in ways that help the firm change adaptively and be responsive to the needs of its markets and actions of its rivals. A lack of autonomy would likely result in passivity when change is needed to initiate effective 
response to opportunities and threats to performance. The presence of autonomy, in contrast, should encourage a greater flexibility in the firm to facilitate active and reactive response to change. Although some framework of coordination is likely to be needed, on balance we expect that autonomy will be beneficial to improving business performance. So, it is hypothesized that:

Hypothesis 5: Autonomy is positively related to business performance.

\section{RESEARCH METHODOLOGY}

\section{Data Generation and Sampling Issues}

As explained at the outset, this study examines issues of EO and business performance in emerging young firms. More specifically, we look at emerging young high-technology firms because entrepreneurship is a particularly salient issue to these types of firms. To characterize high-technology, we adopted Doran and Gunn’s (2002) definition of high-technology firms. These authors define such firms on the following basis; they must: employ highly-skilled employees; emphasize research and development; and, utilize new technology rendering existing technology vulnerable to obsolete.

To capture suitable young high-technology firms at an emerging stage of development as defined by our research goals, we selected firms located within business incubators. Extant research into business incubation (e.g., Hansen, Chesbrough, Nohria, and Sull, 2000) suggests that high-technology incubators will typically host entrepreneurial firms in the sense defined by Lumpkin and Dess (1996) amongst others. Within incubators, a firm is surrounded by likeminded and similarly situated firms which can motivate efforts to be entrepreneurial (Kambil, Eselius and Monteiro, 2000). Incubators also encourage what is perceived as best practice (e.g., Rice 2002), which may encourage a firm toward, for example, entrepreneurial activities. However, incubation and success is neither inevitable or path dependent. Performance comes 
from the practice, actions and activities of the emerging young firm. Accordingly, adopting such a context is suitable to the study of emerging young firms since incubators are a direct sample source of emerging young firms and, so far, we have little knowledge on how such firms should be entrepreneurial or the value of each EO dimension separately to performance.

To create a suitable sample, we needed to access high-technology incubating firms located in high-technology incubators. First, a sampling frame was compiled using the United Kingdom Business Incubation (UKBI) directory of business incubators then, after screening for high-technology oriented incubators, we built a database of the emerging firms within those incubators to serve as our sample population. The Directory was screened for those that could be classified as containing high-technology incubating firms. We found $73 \%$ of all incubators to meet our high-technology criteria, thus providing a rich sample source. These incubators hosted young firms operating in science, bioscience, technology, and knowledge-based businesses; engineering businesses; and computing, IT, and internet-related businesses. We then generated a random sample of 1,000 emerging young high-technology firms from the database of firms we had built based on the latter screening. We emphasize that incubating firms were surveyed, not incubators.

We then considered potential informants in each sampling unit. For an informant to be suitable for the information needs of the study, the informant had to be in a position to provide the relevant information in a knowledgeable manner, thus of senior management level. Although firms possess many types of key informants (Kumar, Stern, and Anderson, 1993), top-level managers, such as the Managing Director in this case, are the principle source of information about strategic processes and are arguably the only source of information about aspects that involve the whole of the firm (Norburn, 1989), particularly so in smaller entrepreneurial firms. 
Such informants are knowledgeable of internal and external issues to the firm, have similar responsibilities regardless of firm size or scope (Norburn, 1989), and are in the best position to provide key insights into firm practices, processes, and outcomes (Huber and Power, 1985; Stubbart, 1989). Accordingly, given the nature of the constructs and our information needs, it was decided that the Managing Director of the emerging young high-technology firms would be the most appropriate key informant to provide the information sought.

To generate data, a mail survey was administered adhering, as far as was feasible, to the principles of the Tailored Design Method (Dillman, 2000). Pre-notification correspondence, questionnaire package, and a series of first and second follow-up reminders were sent respectively to sampling units. Good practice recommended by Dillman (2000) concerning questionnaire salience, length, return postage, anonymity guarantee, and university sponsorship were integrated into survey implementation. A total of 211 eligible questionnaires were received, generating a 21\% response rate. Although our response rate may prima facie appear low, it is offset in part by the fact that many potential respondents declined to participate $(n=82)$ for a variety of reasons. The reasons ranged from, firms having relocated through to the fact the Managing Directors of young high-technology firms are extremely busy, a degree of apathy toward mail surveys in the U.K., the fact that mail surveys may have become victims of their own success such that managers are swamped by them (Ibeh, Brock, and Zhou, 2004), and that the perceived length of the instrument relative to perceived completion time may have been unfavorable. However, the response rate remains comparable to those of other studies in this area (e.g., Hult and Ketchen, 2001; Hult et al., 2004; Morgan and Strong, 2003) and those found in studies of response rates more generally (e.g., Erdogan and Baker, 2002; Greer, Chuchinprakarn, and Seshadri, 2000; see also Larson and Chow, 2003). 
Respondent firms had a median size of 6 full-time employees, an age of 2.5 years, and turnover in the previous 12-month period of GBP 400,000. To test for non-response bias, the Armstrong and Overton (1977) extrapolation method was employed, which is the accepted method for such a test. No significant differences, at conventional levels, between early and late respondents across the range of measurement scales were evident. Based on this result, we can be reassured that non-response bias does not exist within the data.

\section{Operationalization and Measurement}

All items used to measure constructs were gauged on seven-point Likert-type scales. EO dimensions and business performance dimensions were measured using statements anchored "Strongly disagree" (1) to "Strongly agree" (7). These measures were mostly sourced from previous studies with some modification made following pre-tests. The work of Lumpkin and Dess (1996) was used as a guide in developing scales for EO dimensions. The risk-taking (RISK) measures were sourced from Barringer and Bluedorn (1999), Hornsby, Kuratko, and Zahra (2002), and Morgan and Strong (2003), with some items from Hult and Ketchen (2001). Innovativeness (INNOV) measures were mostly sourced from the work of Calantone et al. (2002). Proactiveness (PROACTIVE) was derived from the work of Bateman and Crant (1993), Hult and Ketchen (2001), and Morgan and Strong (2003). Competitive aggressiveness (COMPAGG) measures were based on those used by Lumpkin and Dess (2001). The autonomy (AUTONOMY) measures were developed from Engel (1970), Hornsby et al. (2002), and Spreitzer (1995).

In examining business performance, we used two dimensions: customer performance and product performance. A firm's customer performance is usually characterized by customer acquisition and customer retention (e.g., Hansotia, 2004; Jayachandran, Sharma, Kaufman, and 
Raman, 2005; Reinartz, Thomas, and Kumar, 2005; Thomas, 2001). For emerging young firms to survive and prosper, it is imperative that they attract new customers, sustain its existing customer base, and achieve repeat orders. Customer performance (CUSTPERF) measures were thus developed based on how effective the firm had been at attracting, retaining and sustaining customers and achieving repeated orders. This was salient because emerging firms must seize customers quickly with a sound competitive offering if they are to survive in the short-term and develop a platform for future profitability.

Product performance (PRODPERF) measures were based on the relative success of the firm's products in terms of sales and at achieving market share. Support for these measures is drawn from the new product performance research of Atuahene-Gima and Li (2004), Song and Xie (2000), and Wei and Morgan (2004). Since emerging young firms often base their market approach and their success typically on one core product offering, it was sensible to capture the relative success of the emerging firm's products at securing sales and market share compared to competitors as these dimensions capture the two key areas in which emerging young firms must make an impact if they are to survive and prosper.

To ensure face and content validity, the questionnaire was subjected to review and finally pre-tested with a number of expert judges consisting of academicians, managers, and field experts. Various alterations were made to the items. The items we used to capture each construct can be found in the Appendix. Summated scales were constructed for each construct. To test for reliability, Cronbach alpha coefficients were calculated for each scale, all of which successfully satisfied Nunnally's (1978) threshold level of reliability with alpha coefficients of 0.70 or greater in each case (Table 1 ). The validity of each scale was gauged by item-total 
correlation analyses (Appendix). All item-total correlation coefficients were found to be acceptably high, in the anticipated direction, and statistically significant $(p \leq .001)$.

[Insert Table 1 about here]

\section{RESULTS \& ANALYSIS}

Table 1 contains a correlation matrix of all the constructs to illustrate inter-relationships among these constructs. Initial inspection of the correlation matrix suggests that mixed support exists for our hypotheses that the five EO dimensions contribute to business performance. Innovativeness and proactiveness are both correlated with product performance and customer performance. However, the remaining three EO dimensions show no correlation with either performance dimension. This finding is important because it signals that, at an emerging stage of development, not all EO dimensions are equally or necessarily associated with business performance. This supports the words of Lumpkin and Dess (1996) who cautioned that each dimension of EO may not necessarily be equally valuable or desirable to improve business performance at different stages of firm development. Our findings signal that adopting a gestalt approach to the study of EO potentially masks weaknesses in its real value to firms. Moreover, firms need not necessarily pursue all EO dimensions and cannot expect each dimension to be necessarily associated with improved performance. Nevertheless, these are only bivariate relationships. Multiple regression analyses were performed to further test hypotheses and these results are contained within Table 2.

[Insert Table 2 about here]

The results in Table 2 are presented in terms of the relation of each EO dimension to each dimension of business performance. Each regression model possesses statistically significant $F$ test scores and so we can be confident that the models possess good explanatory power. We 
tested the variance inflation factor and condition index statistics and found that multicollinearity was not an issue in the data since they were within tolerable limits set out by Hair, Anderson, Tatham, and Black (1998). The variance inflation factor statistics ranged between 1.00 and 1.58 ( $<10$, Hair et al., 1998). The condition index statistics peaked at 23.55 ( $<30$, Hair et al., 1998). Confidence in the regression tests that follow is therefore provided by these statistics.

The regression results indicate that the relationship between $\mathrm{EO}$ and performance is complex. Hypothesis 3, which predicted a positive relationship between proactiveness and performance, is supported on both performance dimensions. Proactiveness is the only EO dimension to be related to improvements in both product performance $(\beta=0.23, p<0.01)$ and customer performance ( $\beta=0.35, p<0.01$ ). Therefore, it must form a central component of an emerging young firm's entrepreneurial strategy. Hypothesis 2 is somewhat supported in that innovativeness is positively related to product performance ( $\beta=0.16, p<0.1)$ but not customer performance. This confirms Lumpkin and Dess' (1996) suspicion that on different performance metrics, EO dimensions may yield different outcomes. Hypothesis 1 (risk-taking) is refuted on the product performance dimension $(\beta=-0.14, p<0.1)$ which demonstrates that each dimensions might not necessarily be desirable in pursuing improved performance. Hypotheses 4 and 5 attract no support on either performance dimension and serve to reinforce the concerns raised at the beginning of this paper that each EO dimension, under certain circumstances, may not be of any use in trying to secure superior performance.

We find little evidence, therefore, to support the widely held belief that EO is universally beneficial for business performance. Indeed, our findings illustrate that adopting a gestalt approach to examining EO masks the fact that performance improvements might be the product of only one or two of its five dimensions and that its remaining components are either of no 
value or even work against initiatives to improve performance. At an embryonic stage of development, therefore, firms need to take a cautious approach to implementing EO as all its dimensions do not guarantee improved performance. Our research therefore goes some way to explaining contradictions found in research that have examined the EO-performance relationship. First, contradictions might be a product of firms being examined at different stages of development thus facing different conditions and needs. Second, contradictions might result from the gestalt study of EO whereby only one or a combination of strong dimensions exhibit performance outcomes (thereby inflating the strength of the overall EO construct) or show very little cumulative impact (thereby deflating any influence by a valuable component). Our findings caution managers and researchers from assuming that each dimension is equally valuable or universally valid in studying business performance.

\section{CONCLUSIONS, IMPLICATIONS, \& LIMITATIONS}

Through this study, we sought to explore whether each dimension of EO, as conceptualized by Lumpkin and Dess (1996), was equally valuable in securing improved performance. Specifically, we aimed to address a central caveat in Lumpkin and Dess' (1996) seminal work that, potentially, these dimensions might have no or even a negative relationship with performance depending on different circumstances. In this regard, we wanted to rectify glaring omissions in the study of EO. To our knowledge, this is the first study of its kind to consider all five dimensions of EO on business performance independently without adopting a gestalt approach to measuring EO and is the first to examine firms at a specific stage of development, in this case at an embryonic stage of development.

It is interesting that emerging young firms, which could be thought of as inherently entrepreneurial, struggle to achieve strong business performance and their use of an EO may 
actually be contributing to this difficulty. Liabilities of newness may explain why this occurs. With weak resource and knowledge endowments, these firms may be unable to make full and effective use of an EO, which is resource intensive when implemented in full. An examination of frequencies reveals that firms in our sample make relatively intensive use of each EO dimension. On the 7-point scale employed, the mean of risk-taking (5.05), innovativeness (5.65), proactiveness (5.33), competitive aggressiveness (4.74), and autonomy (5.65) were all relatively strong across the sample which shows that the issue of EO is highly pertinent. However, this equally demonstrates a misapplication of resources since the findings show that performance implications vary significantly. Emerging young firms therefore must tread carefully and apply EO strategically to ensure each feature contributes to performance and adds value to the firm. An ad hoc approach to the implementation of EO is potentially damaging since it unwittingly leads to a waste of resources and consequently leads to an unintended strategic decision to undermine the firm's performance.

Our results demonstrate that, at this particular stage of development, proactiveness and innovativeness are the primary features of an EO responsible for improving business performance. Risk taking negatively influences product performance and competitive aggressiveness and autonomy indicate no influence whatsoever on either business performance dimension. When EO is deconstructed into its five component dimensions, it becomes clear that each dimension is not equally valuable to performance at an embryonic stage of development.

A primary research question that emerges is at which stages of development do the other dimensions of EO become valuable. Intuitively, they might benefit performance at a later stage because they encourage firms to avoid inertia when fast growth plateaus. However, there are costs to risk-taking and aggressiveness too—typically from competitor responses—and 
autonomy might lead to drift and resource wastage if there is no coordinating mechanism in place to inform the direction of autonomous behavior. Surprisingly, little research exists into the potential costs of EO dimensions as the tendency has been to assume a unilateral positive relationship with performance. Research into EO would therefore benefit from exploring indirect relationships as well as testing its own assumptions further. Nevertheless, our findings help shed light on how EO might contribute to advantage and we caution researchers and managers alike to examine EO with great care and assess objectively whether its dimensions add or detract from value in the firm.

\section{Conclusions}

The findings indicate that uniform effort in all EO dimensions does not generate consistent gains in business performance. However, we can construe from these results that higher levels of proactiveness and innovativeness are correspondingly associated with higher levels of performance in emerging young firms. The relationship between EO and performance is more complex than is often portrayed and we contend that collectively EO dimensions have seemingly little direct influence on business performance. We thereby join a growing list of studies that have come to a similar conclusion (e.g., Matsuno et al., 2002; Morgan and Strong, 2003). It is a research priority to understand why such marked differences have been reported.

Our results might be explained by the fact we examined firms at an embryonic stage of development. For such firms, organizing activities around proactiveness, and to some extent innovativeness, is essential to securing improved performance. Proactiveness encourages the firm to anticipate and act in advance of market change which allows the firm to manage its market and shape the direction of competition over time. Innovativeness then orients the firm to generate novel competitive offerings to meet market needs identified through proactive scanning. 
In conjunction, these two can be powerful processes in the pursuit of performance as the results suggest. For emerging young firms, securing a firm foothold in their chosen marketplace is critical to securing longer-term prosperity and these two activities are highly compatible with that goal. Overall, our findings suggest that deploying EO dimensions is not only a matter of strategic choice, but the selection of dimensions to be implemented must be based on what is beneficial to the strategy pursued and what is appropriate at each stage of development. The EO construct should not be misconstrued as a pathway to advantage since we show that not each dimension is of value. However, if it is applied strategically and selectively it would appear to be beneficial to the emerging young firm.

\section{Implications for Managers and Practitioners}

Managers should revisit their EO capabilities and audit whether these are delivering value. This will require a review of polices and procedures in addition to benchmarking these activities to identify whether the firm is dedicating an unwarranted and misplaced amount of resources to a given EO activity. A value analysis should be undertaken in light of our findings. As Lumpkin and Dess (1996) rightly noted, each dimension can vary independently, indicating that firms should manipulate only those that add value, as highlighted in our results.

The blind pursuit of uniform implementation of EO dimensions is not an effective way for firms to create advantage. Our results suggest that such an attempt would lead to resource inefficiencies since not all EO dimensions are necessarily beneficial. Firms should focus on practices of proactiveness and innovativeness as well as ensuring that risk-taking does not become a hindrance to performance. This does not mean a return to bureaucratic formalization of firms, but, restraint is needed in the application of EO dimensions. 
The key activity for firms is proactiveness given its universal positive influence on both performance metrics. Managers therefore need to ensure that their firms are highly proactive. This will likely require a review and revision of existing practices and activities within the firm. Proactiveness can be improved through the implementation of environmental scanning techniques, a means by which managers can learn about events and trends in the firm's environment, which ultimately aids market opportunity recognition (Hambrick, 1981) so that the firm can generate a step-ahead advantage in meeting expressed and latent needs. Market signal detection and discriminating between opportunities and threats should be the responsibility of all employees, underlining the importance of connecting entrepreneurial efforts to marketing efforts (e.g., Atuahene-Gima and Ko, 2001; Bhuian, Menguc and Bell, 2005; Matsuno et al., 2002; Slater and Narver, 1995). Ensuring adequate involvement and participation in the firm's selected EO activities is essential to this. Other schemes to improve proactiveness include encouraging the use of initiative and allowing improvisation. Such flexible, initiative-led behavior will help the firm shape market direction rather than be governed by it. Also, as suggested by our results, proactiveness should be complemented by innovativeness given that it correlated with performance. Thus, creativity initiatives should also receive management attention and employees should be encouraged to solve market problems in novel ways so that the emerging young firm has a basis to better meet needs and differentiate from rivals.

Effective adoption and execution of proactiveness and innovativeness is likely to require an investment in human capital. Since it is the responsibility of people within the firm to execute proactiveness and innovativeness in its daily routines and marketing efforts, managers should consider what education or skills training might assist employees to perform these activities better. Strong human capital is needed to lever the ability of the firm as a whole to perform 
certain activities to a superior level relative to competitors (Hitt and Ireland, 2002). An investment in human capital to leverage the application of proactiveness and innovativeness will aid their performance impact. This corresponds to the views of Bateman and Crant (1993) regarding the role of employees in proactive firm behavior.

A further implication of our findings is that managers should be mindful in undertaking risk-taking, competitive aggressiveness, or autonomy and consider cautiously whether these are worthwhile at an early stage of development. Our results suggest they contribute no direct value to performance. Risk-taking is considered a defining characteristic of being entrepreneurial. However, we find no evidence that adopting a risk-taking approach to business is beneficial. On the contrary, it would appear to hinder performance. Managers of emerging young firms should consider moving away from treating EO as a cumulative construct and instead focus on its valueadding dimensions to improve performance.

\section{Limitations}

First, our study concentrated on emerging young high-technology firms in the U.K. Caution should therefore be exercised in generalizing these findings to non-comparable populations. Consequently, future studies might want to consider the implications of our work for different populations of firms. Second, we adopted a cross-sectional design but this has the effect of constraining the strength of the causal inferences we can make. A study using a longitudinal design might help to elucidate the findings further, particularly to see whether the effect of different EO dimensions change over time as the firm moves into different stages of development.

\section{Future Research}


Our results do not bear out the notion that EO is uniformly beneficial for business performance. Much further research is needed to identify the causes of anomalies in the EOperformance relationship. The fact that several studies have now found little or no relationship suggests further investigation of this relationship is necessary. In this study, we deconstructed EO into its dimensions and studied these on performance. We also examined specifically firms at an embryonic stage of development. We provide support for concerns raised by Lumpkin and Dess (1996) that at different stages of development and on different performance metrics, each EO dimension may not be equally valuable or necessary. We therefore extend prior research and fill several omissions in EO research.

Questions still remain however. First, at what point in time or in the evolution of firms do other dimensions of EO become important or less important? We suggest that much more research is needed to explore EO at different stages of development to appreciate why inconsistencies have been reported in the relationship between EO and performance. An effective EO strategy cannot remain static and so this is a key issue requiring urgent research. Second, is there an interaction among the EO dimensions that somehow levers performance indirectly? We have not considered the possibility that specific EO dimension might leverage others. Correlations reported in Table 1 suggest that some interaction among the dimension might true yet existing research has not tackled this issue. Third, do EO dimension indirectly influence business performance through some other mechanism? Some recent studies have considered whether EO indirectly influences business performance through market orientation (e.g., Atuahene-Gima and Ko, 2001; Bhuian et al., 2005; Matsuno et al., 2002) and results have been mixed. Research is needed to examine whether there is a stronger case for an indirect relationship than a direct one and what constructs might mediate that relationship. 
Further research is also needed to understand how different EO dimensions might influence other aspects of business development, marketing success, and business process outcomes above and beyond simply business performance. This is necessary to identify whether the strategic selection issue identified in this study extends more broadly to other outcomes as well. Firms and their managers need more information on whether different EO dimensions have differential weights on other dimensions of firm success. So far, a uniform approach has tended to prevail, promoting unquestionably the EO of firms. Nonetheless, as the findings of this study show, there are selective triggers which lead to specific outcomes. Consequently, more research is needed to understand the configuration of EO most suited to achieving different outcomes. 


\section{REFERENCES}

Armstrong, J.S. and T.S. Overton (1977), “Estimating Non-Response Bias in Mail Surveys”, Journal of Marketing Research, Vol. 14, No. 3, pp.396-402.

Atuahene-Gima, K. and A. Ko (2001), “An Empirical Investigation of the Effect of Market Orientation and Entrepreneurship Orientation Alignment on Product Innovation”, Organization Science, Vol. 12, No. 1, pp.54-74.

and Li, H. (2004), "Strategic Decision Comprehensiveness and New Product Development Outcomes in New Technology Ventures”, Academy of Management Journal, Vol. 47, pp.583-597.

Baird, I.S. and W. Thomas (1990), "What is Risk Anyway? Using and Measuring Risk in Strategic Management”, in R.A. Bettis and H. Thomas (Eds.), Risk, Strategy, and Management. Greenwich, CT: JAI Press, pp.21-52.

Barringer, B.R. and A.C. Bluedorn (1999), “The Relationship between Corporate Entrepreneurship and Strategic Management”, Strategic Management Journal, Vol. 20, No. 5, pp.421-444.

Bateman, T.S. and J.M. Crant (1993), “The Proactive Component of Organizational Behavior: A Measure and Correlates”, Journal of Organizational Behavior, Vol. 14, No. 2, pp.103118.

Bhuian, S.N., B. Menguc and S.J. Bell (2005), “Just Entrepreneurial Enough: The Moderating Effect of Entrepreneurship on the Relationship between Market Orientation and Performance”, Journal of Business Research, Vol. 58, pp.9-17.

Brüdel, J. and P. Preisendörfer (2000), “Fast-Growing Businesses”, International Journal of Sociology, Vol. 30, pp.45-70.

Busenitz, L.W. and J.B. Barney (1997), "Differences between Entrepreneurs and Managers in Large Organizations: Biases and Heuristics in Strategic Decision-Making”, Journal of Business Venturing, Vol. 12, pp.9-30.

Calantone, R.J., S.T. Çavuşgil, and Y. Zhao (2002), "Learning Orientation, Firm Innovation Capability, and Business performance”, Industrial Marketing Management, Vol. 31, pp.515-524.

Chen, M.J. and D.C. Hambrick (1995), "Speed, Stealth, and Selective Attack: How Small Firms Differ from Large Firms in Competitive Behavior", Academy of Management Journal, Vol. 38, No. 2, pp.453-482. 
Cho, H.-J. and V. Pucik, (2005), “Relationship between Innovativeness, Quality, Growth, Profitability, and Market Value”, Strategic Management Journal, Vol. 26, pp.555-575.

Covin, J.G. and D.P. Slevin (1989), "Strategic Management of Small Firms in Hostile and Benign Environments”, Strategic Management Journal, Vol. 10, No. 1, pp.75-87. and (1991), “A Conceptual Model of Entrepreneurship as Firm Behavior”, Entrepreneurship Theory and Practice, Vol. 16, pp.7-24.

Davidson, H. (1987), Offensive Marketing: How to Make Your Competitors Followers. London: Penguin.

Day, G.S. and R. Wensley (1988), “Assessing Advantage: A Framework for Diagnosing Competitive Superiority”, Journal of Marketing, Vol. 52, No. 2, pp.1-20.

Dickson, P.R. and J.J. Giglierano (1986), "Missing the Boat and Sinking the Boat: A Conceptual Model of Entrepreneurial Risk”, Journal of Marketing, Vol. 50, No. 3, pp.58-70.

Dillman, D.A. (2000), Mail and Internet Surveys: The Tailored Design Method, $2^{\text {nd }}$ Edition. New York: John Wiley \& Sons, Inc.

Doran, G.T. and J. Gunn (2002), "Decision Making in High-Tech Firms: Perspectives of Three Executives”, Business Horizons, Vol. 45 (November-December), pp.7-16.

Dreyer, B. and K. Grønhaug (2004), “Uncertainty, Flexibility, and Sustained Competitive Advantage”, Journal of Business Research, Vol. 57, No. 5, pp.484-494.

Eisenhardt, K.M., (1989), “Making Fast Strategic Decisions in High-Velocity Environments”, Academy of Management Journal, Vol. 27, pp.299-343.

Engel, G.V. (1970), “Professional Autonomy and Bureaucratic Organization”, Administrative Science Quarterly, Vol. 15, No. 1, pp.12-21.

Erdogan, B.Z. and M.J. Baker (2002), “Increasing Mail Survey Response Rates from an Industrial Population: A Cost-Effectiveness Analysis of Four Follow-Up Techniques”, Industrial Marketing Management, Vol. 31, No.1, pp.65-73.

Garud, R. and P. Nayyar, (1994), “Transformative Capacity: Continual Structuring by Intertemporal Technology Transfer”, Strategic Management Journal, Vol. 15, pp.365-385.

Greer, T.V., N. Chuchinprakarn, and S. Seshadri (2000), "Likelihood of Participating in Mail Survey Research: Business Respondents’ Perspectives”, Industrial Marketing Management, Vol. 29, No. 2, pp.97-109. 
Grewal, R. and P. Tansuhaj (2001), “Building Organizational Capabilities for Managing Economic Crisis: The Role of Market Orientation and Strategic Flexibility”, Journal of Marketing, Vol. 65, No. 2, pp.67-80.

Hair, Jr., J.F., R.E. Anderson, R.L. Tatham, and W.C. Black (1998), Multivariate Data Analysis, $5^{\text {th }}$ Edition. Upper Saddle River, NJ: Prentice-Hall.

Hambrick, D.C. (1981), "Specialization of Environmental Scanning Activities among Upper Level Executives:, Journal of Management Studies, Vol. 18, pp.299-320.

Hamel, G. and C.K. Prahalad (1991), "Corporate Imagination and Expeditionary Marketing”, Harvard Business Review, Vol. 69, July-August, pp.81-92.

Han, J., N. Kim, and R. Srivastava (1998), “Market Orientation and Organizational Performance: Is Innovation a Missing Link?”, Journal of Marketing, Vol. 62, No. 4, pp.30-45.

Hansen, M.T., H.W. Chesbrough, N. Nohria, and D.N. Sull (2000), "Networked Incubators: Hothouses of the New Economy”, Harvard Business Review, Vol. 78, No. 5, pp.74-84.

Hansotia, B. (2004), "Customer Metrics and Organisational Alignment for Maximising Customer Equity”, Journal of Database Marketing \& Customer Strategy Management, Vol. 12, No. 1, pp.9-20.

Hart, S. (1992), “An Integrative Framework for Strategy-Making Processes”, Academy of Management Review, Vol. 17, pp.327-351.

Hitt, M.A. and R.D. Ireland (2002), “The Essence of Strategic Leadership: Managing Human and Social Capital”, Journal of Leadership and Organisation Studies, Vol. 9, No. 1, pp.314.

Hornsby, J.S., D.F. Kuratko, and S.A. Zahra (2002), “Middle Managers' Perception of the Internal Environment for Corporate Entrepreneurship: Assessing a Measurement Scale”, Journal of Business Venturing, Vol. 17, pp.253-273.

Huber, G.P. and R. Power (1985), "Retrospective Reports of Strategic-Level Managers: Guidelines for Increasing their Accuracy”, Strategic Management Journal, Vol. 6, pp.171180.

Hult, G.T.M. and D.J. Ketchen, Jr. (2001), “Does Market Orientation Matter?: A Test of the Relationship Between Positional Advantage and Performance”, Strategic Management Journal, Vol. 22, No. 9, pp.899-906.

, R.F. Hurley, and G.A. Knight (2004), “Innovativeness: Its antecedents and Impact on Business Performance”, Industrial Marketing Management, Vol. 33, pp.429-438. 
Hurley, R.F. and G.T.M. Hult (1998), "Innovation, Market Orientation, and Organizational Learning: An Integration and Empirical Examination”, Journal of Marketing, Vol. 62, No. 3, pp.42-54.

Ibeh, K., J.K.-U. Brock, and Y.J. Zhou (2004), “The Drop and Collect Survey among Industrial Populations: Theory and Empirical Evidence”, Industrial Marketing Management, Vol. 33, No. 2, pp.155-165.

Jayachandran, S., S. Sharma, P. Kaufman, P. Raman (2005), “The Role of Relational Information Processes and Technology Use in Customer Relationship Management”, Journal of Marketing, Vol. 69, October, pp.177-192.

Kambil, A., E.D. Eselius, and K.A. Monteiro (2000), "Fast Venturing: The Quick Way to Start Web Businesses”, Sloan Management Review, Vol. 41, No. 4, pp.55-67.

Kumar, N., L.W. Stern, and J.C. Anderson (1993), “Conducting Interorganizational Research Using Key Informants”, Academy of Management Journal, Vol. 39, No. 2, pp.340-367.

Larson, P.D. and G. Chow (2003), "Total Cost/Response Rate Trade-Offs in Mail Survey Research: Impact of Follow-Up Mailings and Monetary Incentives", Industrial Marketing Management, Vol. 32, No. 7, pp.533-537.

Lee, C., K. Lee, and J.M. Pennings (2001), "Internal Capabilities, External networks, and Performance: A Study on Technology-Based Ventures”, Strategic Management Journal, Vol. 22, pp.615-640.

Lumpkin, G.T. and G.G. Dess (1996), "Clarifying the Entrepreneurial Orientation Construct and Linking it to Performance”, Academy of Management Review, Vol. 21, No. 1, pp.135-172.

and G.G. Dess (2001), "Linking Two Dimensions of Entrepreneurial Orientation to Business performance: The Moderating role of Environment and Industry Life Cycle”, Journal of Business Venturing, Vol. 16, pp.429-451.

Matsuno, K., J.T. Mentzer, and A. Özsomer (2002), “The Effects of Entrepreneurial Proclivity and Market Orientation on Business Performance”, Journal of Marketing, Vol. 66, July, pp.18-32.

Miller, D. (1983), “The Correlates of Entrepreneurship in Three Types of Firms”, Management Science, Vol. 29, pp.770-791.

and P.H. Friesen (1978), “Archetypes of Strategy Formulation”, Management Science, Vol. 24, pp.921-933.

and (1982), "Innovation in Conservative and Entrepreneurial Firms: Two Models of Strategic Momentum”, Strategic Management Journal, Vol. 3, pp.1-25. 
Morgan, R.E. and C.A. Strong (2003), "Business Performance and Dimensions of Strategic Orientation”, Journal of Business Research, Vol. 56, No. 3, pp.163-176.

Naman, J.L. and D.P. Slevin (1993), "Entrepreneurship and the Concept of Fit: A Model and Empirical Tests”, Strategic Management Journal, Vol. 14, pp.137-153.

Norburn, D. (1989), “The Chief Executive: A Breed Apart”, Strategic Management Journal, Vol. 10, pp.1-15.

Nunnally, J.C. (1978), Psychometric Theory, $2^{\text {nd }}$ Edition. New York: McGraw-Hill.

Reinartz, W., J.S. Thomas, and V. Kumar (2005), "Balancing Acquisition and Retention Resources to Maximize Customer Profitability”, Journal of Marketing, Vol. 69, January, pp.63-79.

Rice, M.P. (2002), “Co-production of Business Assistance in Business Incubators: An Exploratory Study”, Journal of Business Venturing, Vol. 17, pp.163-187.

Slater, S.F. and J.C. Narver (1995), "Market Orientation and the Learning Organization”, Journal of Marketing, Vol. 59, July, pp.63-74.

and E.M. Olson (2002), “A Fresh Look at Industry and Market Analysis”, Business Horizons, Vol. 45, No. 1, pp.15-22.

Slevin, D.P. and J.G. Covin (1990), “Juggling Entrepreneurial Style and Organizational Structure”, Sloan Management Review, Vol. 31, No. 2, pp.43-53.

Smart, D.T. and J.S. Conant (1994), "Entrepreneurial Orientation, Distinctive Marketing Competencies, and Organizational Performance” Journal of Applied Business Research, Vol. 10, No.3, pp.28-38.

Song, X.M. and J. Xie (2000), "Does Innovativeness Moderate the Relationship Between CrossFunctional Integration and Product Performance?”, Journal of International Marketing, Vol. 8, No. 4, pp.61-89.

Spreitzer, G.M. (1995), "Psychological Empowerment in the Workplace: Dimensions, Measurement, and Validation”, Academy of Management Journal, Vol. 38, No. 5, pp.14421465.

Stubbart, C. (1989), "Managerial Cognition: A Missing Link in Strategic Management Research”, Journal of Management Studies, Vol. 26, pp.325-347.

Thomas, J.S. (2001), “A Methodology for Linking Customer Acquisition to Customer Retention”, Journal of Marketing Research, Vol. 38, No. 2, pp.262-268. 
Venkatraman, N. (1989), “Strategic Orientation of Business Enterprises: The Construct, Dimensionality, and Measurement”, Management Science, Vol. 20, pp.510-540.

Wei, Y. and N.A. Morgan (2004), "Supportiveness of Organizational Climate, Market Orientation, and New Product Performance in Chinese Firms”, Journal of Product Innovation Management, Vol. 21, Pp.375-388.

Wiklund, J. (1999), “The Sustainability of the Entrepreneurial Orientation-Performance Relationship”, Entrepreneurship Theory \& Practice, Vol. 24, No. 1, pp.37-48.

and D. Shepherd (2003), “Knowledge-Based Resources, Entrepreneurial Orientation, and the Performance f Small and Medium-Sized Businesses”, Strategic Management Journal, Vol. 24, pp.1307-1314. and (2005), "Entrepreneurial Orientation and Small Business Performance: A Configurational Approach”, Journal of Business Venturing, Vol. 20, pp.7191.

Wright P., M. Kroll, B. Pray, and A. Lado (1995), “Strategic Orientations, Competitive Advantage, and Business Performance”, Journal of Business Research, Vol. 33, pp.143151.

Zahra, S.A. (1991), "Predictors and Financial Outcomes of Corporate Entrepreneurship: An Explorative Study”, Journal of Business Venturing, Vol. 6, pp.259-285.

Zahra, S.A. and J. Covin (1995), "Contextual Influences on the Corporate EntrepreneurshipPerformance Relationship: A Longitudinal Analysis”, Journal of Business Venturing, Vol. 10, pp.43-58. 


\section{APPENDIX}

\section{Measures and Items Used}

Scale composition

Entrepreneurial Orientation:

Risk-taking (RISK)

The term 'risk taker' is considered a positive attribute for people in our business

People in our business are encouraged to take calculated risks with new ideas

Our business emphasizes both exploration and experimentation for opportunities

Innovativeness (INNOV)

We actively introduce improvements and innovations in our business

Our business is creative in its methods of operation

Our business seeks out new ways to do things

Proactiveness (PROACTIVE)

We always try to take the initiative in every situation (e.g., against competitors, in projects and when working with others)

We excel at identifying opportunities

We initiate actions to which other organizations respond

Competitive aggressiveness (COMPAGGR)

Our business is intensely competitive

In general, our business takes a bold or aggressive approach when competing

We try to undo and out-maneuver the competition as best as we can

Autonomy (AUTONOMY)

Employees are permitted to act and think without interference

Employees perform jobs that allow them to make and instigate changes in the way they perform their work tasks

Employees are given freedom and independence to decide on their own how to go about doing their work

Employees are given freedom to communicate without interference

Employees are given authority and responsibility to act alone if they think it to be in the best interests of the business

Employees have access to all vital information

Item-total

scale correlation $^{\text {a }}$

0.87

0.83

0.76

0.87

0.86

0.83

0.82

0.82

0.82

0.81

0.83

0.81

0.80

0.83

0.79

0.74

0.75

0.69

Business Performance:

Product performance (PRODPERF)

Relative to competing products, those of our business have been more successful in terms of sales

Relative to competing products, those of our business have been more successful in terms of achieving and establishing market share

Customer performance (CUSTPERF)

We have been able to attract totally new customers this year

We have been able to expand our existing customer base this year

We have succeeded in sustaining our customer base and achieving repeat orders
0.98

0.98

0.90

0.90

0.79

${ }^{\text {a }}$ Pearson Correlation Coefficients. All correlations are significant at the 0.001 level (two-tailed). 
Table 1 - Scale Properties, Descriptive Statistics, and Correlation Matrix of Constructs

\begin{tabular}{|c|c|c|c|c|c|c|c|c|}
\hline Scale label & $\begin{array}{l}\text { Mean } \\
\text { (S.D.) }\end{array}$ & PRODPERF & CUSTPERF & RISK & INNOV & PROACTIVE & COMPAGGR & AUTONOMY \\
\hline PRODPERF & $4.31(1.41)$ & 0.96 & & & & & & \\
\hline CUSTPERF & 5.44 (1.18) & $0.55^{* *}$ & 0.83 & & & & & \\
\hline RISK & $5.05(1.02)$ & 0.03 & 0.09 & 0.77 & & & & \\
\hline INNOV & $5.65(0.97)$ & $0.20 * *$ & $0.16^{*}$ & $0.52 * *$ & 0.81 & & & \\
\hline PROACTIVE & $5.33(0.94)$ & $0.28 * *$ & $0.36 * *$ & $0.27 * *$ & $0.41 * *$ & 0.75 & & \\
\hline COMPAGGR & $4.74(1.32)$ & 0.03 & 0.01 & $0.15^{*}$ & 0.11 & 0.07 & 0.75 & \\
\hline AUTONOMY & $5.46(1.02)$ & 0.10 & 0.08 & $0.30 * *$ & $0.27 * *$ & 0.10 & -0.01 & 0.86 \\
\hline
\end{tabular}

** Correlation is significant at the 0.01 level (two-tailed).

* Correlation is significant at the 0.05 level (two-tailed).

Note: Cronbach Alphas are shown on the diagonal of the correlation matrix in italics. 
Table 2 - Multiple Regression Analysis Results

\begin{tabular}{|c|c|c|c|c|c|}
\hline Model & $\begin{array}{l}\text { Dependent } \\
\text { variable }\end{array}$ & $\begin{array}{l}\text { Independent } \\
\text { variable }\end{array}$ & Model properties & $\begin{array}{c}\text { Standardized regression } \\
\text { coefficient }(\boldsymbol{\beta})\end{array}$ & $t$-value \\
\hline Model 1 & PRODPERF & $\begin{array}{l}\text { RISK } \\
\text { INNOV } \\
\text { PROACTIVE } \\
\text { COMPAGGR } \\
\text { AUTONOMY } \\
\text { Intercept }\end{array}$ & $\begin{array}{l}R^{2}=0.10 \\
F \text {-value }=4.32^{* *}\end{array}$ & $\begin{array}{r}-0.14 \\
0.16 \\
0.23 \\
0.02 \\
0.07\end{array}$ & $\begin{array}{l}-1.69 \dagger \\
1.89 \dagger \\
3.14^{* *} \\
0.30 \\
0.95 \\
1.98^{* *}\end{array}$ \\
\hline Model 2 & CUSTPERF & $\begin{array}{l}\text { RISK } \\
\text { INNOV } \\
\text { PROACTIVE } \\
\text { COMPAGGR } \\
\text { AUTONOMY } \\
\text { Intercept }\end{array}$ & $\begin{array}{l}R^{2}=0.13 \\
F \text {-value }=6.08^{* *}\end{array}$ & $\begin{array}{r}-0.02 \\
0.02 \\
0.35 \\
-0.01 \\
0.05\end{array}$ & $\begin{array}{l}-0.31 \\
0.22 \\
4.89 * * \\
-0.19 \\
0.73 \\
4.38 * *\end{array}$ \\
\hline
\end{tabular}

